\title{
Serum protein microarray analysis of patients with preeclampsia
}

\author{
LEI HOU, YU ZHU, XIAOMIN MA, JIANING LI and WEIYUAN ZHANG
}

Department of Obstetrics, Beijing Obstetrics and Gynecology Hospital, Capital Medical University, Beijing 100026, P.R. China

Received December 12, 2011; Accepted March 26, 2012

DOI: $10.3892 / \mathrm{mmr} .2012 .864$

\begin{abstract}
The present study identified novel factors related to preeclampsia. Serum samples were analyzed using a membrane-based human cytokine microarray technology in patients with preeclampsia. Serum was collected from 29 healthy pregnant subjects, 16 gestational hypertensive patients and 31 patients with preeclampsia. The samples for microarray analysis were randomly selected from 8 subjects, 5 patients with preeclampsia and 3 healthy pregnant controls. Serum was analyzed using a custom human cytokine microarray (RayBio ${ }^{\circledR}$ Custom Human Cytokine Array) designed to analyze 120 specific cytokines simultaneously. The levels of sTNF-R1, Axl and TIMP-2 were further measured by sandwich enzyme-linked immunosorbent assay (ELISA). In microarray analysis, there were no significant differences in most of the measured parameters among the two study groups, except in serum TNF-R1, Axl and TIMP-2 ( $\mathrm{P}=0.021, \mathrm{P}=0.034$ and $\mathrm{P}=0.040$, respectively). ELISA showed that the serum TNF-R1 levels were significantly higher in preeclampsia patients $(288.06 \pm 78.30 \mathrm{pg} / \mathrm{ml})$ compared to patients with gestational hypertension $(229.81 \pm 47.65, \mathrm{P}=0.005)$ and healthy pregnant subjects $(247.48 \pm 59.00, \mathrm{P}=0.009)$. Serum Axl levels were markedly higher in patients with preeclampsia $(2.28 \pm 0.25 \mathrm{ng} / \mathrm{ml})$ compared to patients with gestational hypertension $(2.05 \pm 0.21 \mathrm{ng} / \mathrm{ml})$ and healthy pregnant subjects (2.11 $\pm 0.28, \mathrm{P}=0.005)$. Additionally, preeclamptic patients had higher TIMP-2 levels $(3.33 \pm 1.01 \mathrm{ng} / \mathrm{ml})$ as compared to gestational hypertensive patients $(3.13 \pm 0.56 \mathrm{ng} / \mathrm{ml})$ and healthy pregnant women $(3.00 \pm 0.49 \mathrm{ng} / \mathrm{ml})$, but there was no pronounced difference between the three groups $(\mathrm{F}=1.285$, $\mathrm{P}=0.283>0.05)$. Our results demonstrated that two biological processes related to inflammatory response and endothelium activation are involved in the pathogenesis of preeclampsia.
\end{abstract}

\section{Introduction}

Preeclampsia, an important cause of maternal and perinatal mortality and morbidity, is thought to be a consequence

Correspondence to: Dr Weiyuan Zhang, Department of Obstetrics, Beijing Obstetrics and Gynecology Hospital, Capital Medical University, Beijing 100026, P.R. China

E-mail: proffzhang@163.com

Key words: preeclampsia, microarray, TNF-R1, Axl, TIMP-2 of impaired trophoblastic invasion of the maternal spiral arteries $(1,2)$. This leads to placental hypoxia and the release of inflammatory factors causing endothelial cell activation and damage (3). Cytokines are found to be involved in fetoplacental development, and have been suggested to be the placental factor capable of damaging endothelial cells and contributing to many of the pathophysiological changes associated with preeclampsia (4). We applied cytokine antibody microarray to identify the key factor(s) associated with preeclampsia.

In the present study, we sought to characterize the cytokine profile in the serum of preeclampsic women, using an antibody microarray system (RayBio ${ }^{\circledR}$ Custom Human Cytokine Array). This antibody microarray allows the measurement of 120 proteins in samples of a small volume. This system possesses the advantages of enzyme-linked immunosorbent assay (ELISA) in specificity, enhanced chemiluminescent (ECL) in sensitivity and microspot in high-throughput. With this approach, capture antibodies are spotted onto membranes which are then exposed to a sample containing the proteins of interest. The corresponding antigens bind to their cognate antibodies spotted onto the membranes and are detected by a cocktail of detection antibodies. This system is characterized by high specificity and sensitivity. Utilizing this approach, we characterized the cytokine profiles between preeclamptic pregnant patients and healthy controls aiming to identify novel inflammatory mediators associated with preeclampsia.

\section{Materials and methods}

Subjects. Preeclampsia was defined by increased blood pressure $(\geq 140 \mathrm{mmHg}$ systolic or $\geq 90 \mathrm{mmHg}$ diastolic on two or more examinations with an interval of at least $6 \mathrm{~h}$ apart) that occurs after 20 -week gestation in a woman with previously normal blood pressure, accompanied by proteinuria $(\geq 0.3 \mathrm{~g} / 24 \mathrm{~h}$ or $\geq 1+$ on dipstick examination in the absence of urinary tract infection).

Exclusion criteria included multifetal gestation, chronic hypertension, diabetes mellitus, autoimmune disease, angiopathy, renal disorder, maternal or fetal infection and fetal congenital anomaly. None of the pregnant women were in active labor, and none had rupture of membranes.

The study protocol was approved by the Regional and Institutional Committee of Science and Research Ethics of the Beijing Obstetrics and Gynecology Hospital, Capital Medical University, and written informed consent was obtained from each patient before the study. 
Sample collection. Fasting blood samples were taken from the antecubital vein, and then centrifuged at room temperature for $10 \mathrm{~min}$ at $3,000 \mathrm{x} \mathrm{g}$. Aliquots of serum were stored at $-80^{\circ} \mathrm{C}$ for use.

Cytokine antibody microarray analysis. Serum was diluted to $1: 3$ and probed for the cytokine profile using the RayBio Human Cytokine Antibody Array kit according to the manufacturer's instructions (No. AAH-CYT-G1000; RayBiotech, Norcross, GA, USA). A total of 120 factors were evaluated (for a complete list of factors, refer to www.raybiotech.com) on two slides: series 6 (60 cytokines) and series 7 (60 cytokines), and $50 \mu$ l of samples was incubated on the microarray. Microarray analysis was performed according to the manufacturer's instructions, and the cytokines were detected by fluorescence staining. Films of array dots were scanned with a confocal laser fluorescence scanner (Luxscan-10K/A; CapitalBio, Beijing, China) with a resolution of $10 \mu \mathrm{m}$ per pixel. Both the laser power and photomultiplier gain were set at $70 \%$. Image analysis was carried out with Spot Data Pro 2.0 (CapitalBio), and final values were calculated using G Series 1000 Analysis Tool software (RayBiotech). Data were subtracted for local background and normalized to internal positive and negative controls. Data of healthy pregnant subjects were compared to those of preeclampsic patients using two independent t-tests. A value of $\mathrm{P}<0.05$ was considered to indicate statistical significance.

ELISA. Plasma content of sTNF-R1 (catalog no. DRT100, sTNF-R1; R\&D Systems, Abingdon, UK) was determined using ELISA. The intra-assay variation coefficient was $4.7 \%$ and the interassay variation $8.8 \%$. The TIMP-2 ELISA kit (DTM200) was purchased from R\&D Systems. The intra-assay variation coefficient was $4.4 \%$ and interassay variation $6.8 \%$. Plasma content of Axl (catalog no. ab99976; Abcam, UK) was determined by ELISA. The intra-assay variation coefficient was $<10 \%$ and the interassay variation $<12 \%$. Assays were performed according to the manufacturer's instructions.

Statistical analysis. In the cytokine assay, the results are expressed as the means \pm standard deviation (SD). Data of healthy pregnant subjects and preeclampsia patients were compared using two independent t-tests. In ELISA, data are expressed as the means $\pm \mathrm{SD}$. One-way analysis of variance (ANOVA) was performed to compare the results among different groups. A value of $\mathrm{P}<0.05$ was considered to indicate statistical significance.

\section{Results}

Clinical characteristics. The clinical characteristics of the participants are documented in Table I. There was no statistically significant difference in terms of age, gestational age and body mass index (BMI) between the preeclamptic patients and healthy pregnant women.

Cytokine antibody microarray analysis. Serum of women in the two study groups was exposed to RayBiotech Cytokine Antibody Microarray, and 120 proteins in the microarray were detectable (Fig. 1). There were no significant differences

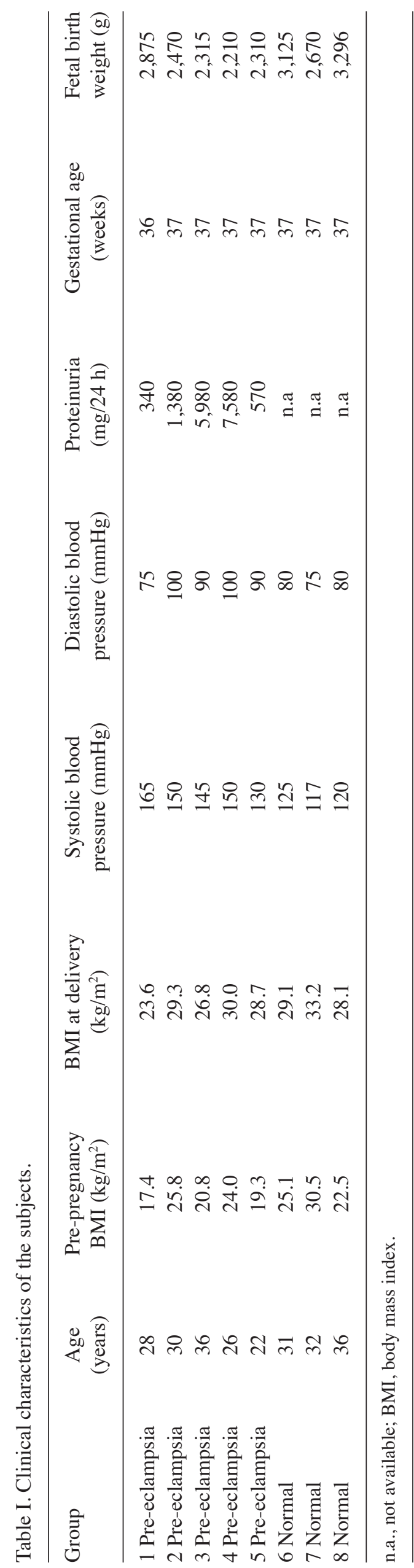



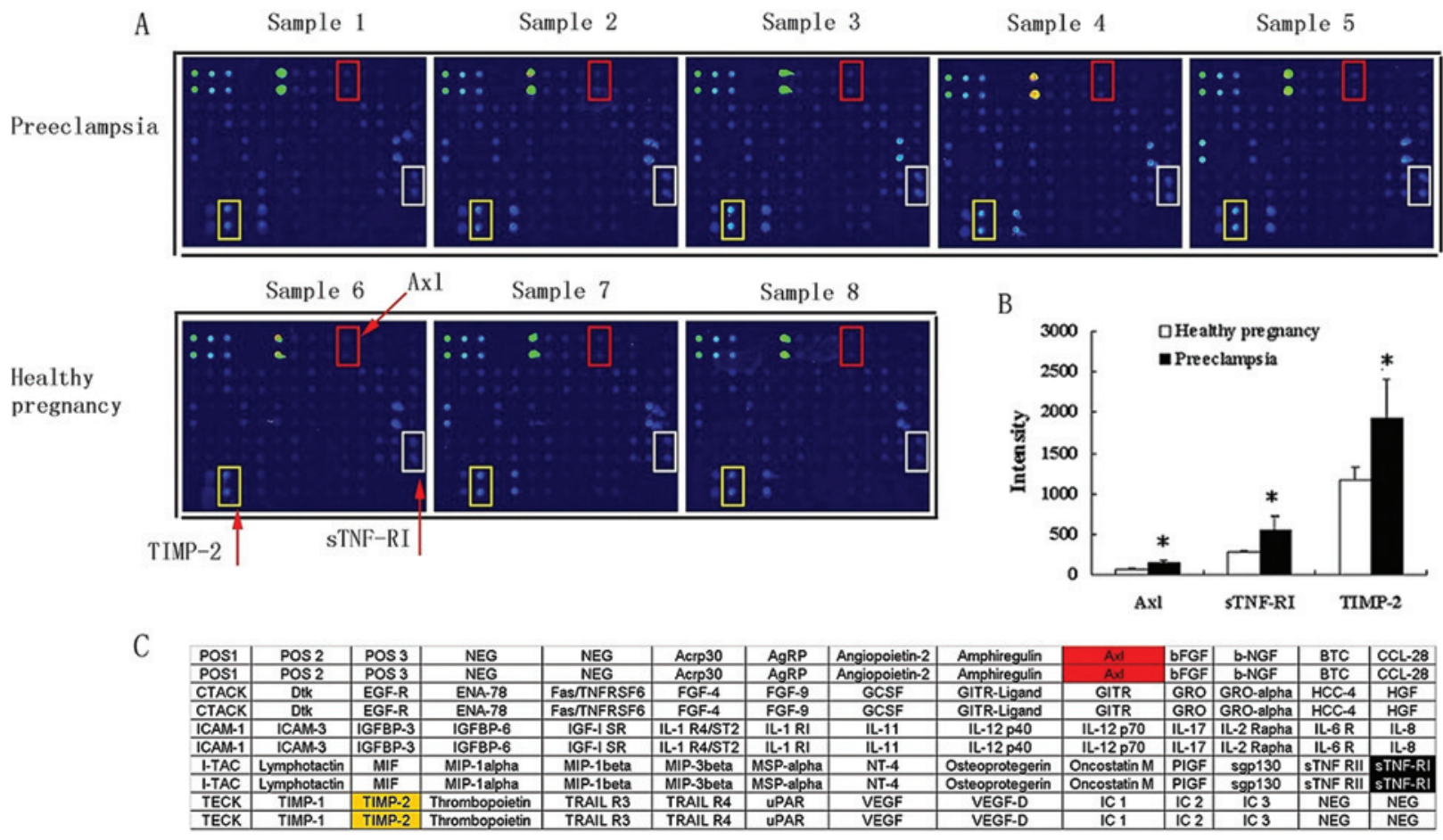

Figure 1. RayBio ${ }^{\circledast}$ Human Cytokine Antibody Microarray (AAH-CYT-G1000), including two slides: series 6 (60 cytokines) and series 7 (60 cytokines). A total of 60 antibodies against cytokines and chemokines were placed on the microarray. (A) Representative membrane protein microarrays were incubated with the serum of 5 preeclamptic subjects (top; A), and 3 healthy pregnant subjects (bottom; A). (B) Preeclampsic women showed significantly increased serum levels of TNF-R1, Axl and TIMP-2 when compared to healthy pregnant women. (C) The names and locations of each cytokine/chemokine custom spots are listed.

Table II. Densitometric values of chemokine/cytokine in the RayBiotech Antibody Microarray analysis (means \pm SD).

\begin{tabular}{|c|c|c|c|c|}
\hline Factor & Preeclampsia $(n=5)$ & Normal pregnancy $(n=3)$ & $\mathrm{t}$ & P-value \\
\hline Axl & $137.00 \pm 38.81$ & $72.67 \pm 10.26$ & -2.732 & 0.034 \\
\hline sTNF-RI & $559.40 \pm 164.14$ & $288.33 \pm 12.70$ & -3.675 & 0.021 \\
\hline TIMP-2 & $1,925.60 \pm 476.25$ & $1,163.67 \pm 156.18$ & -2.614 & 0.040 \\
\hline TGF- $\beta 3$ & $9.00 \pm 2.92$ & $14.00 \pm 1.73$ & 2.652 & 0.038 \\
\hline ICAM-3 & $12.00 \pm 1.87$ & $7.33 \pm 0.58$ & -4.087 & 0.006 \\
\hline
\end{tabular}

in most of the measured parameters between the two study groups, except in serum TNF-R1, Axl, TIMP-2, TGF- $\beta 3$ and ICAM-3 $(\mathrm{P}=0.021, \mathrm{P}=0.034, \mathrm{P}=0.040, \mathrm{P}=0.038$ and $\mathrm{P}=0.006$, respectively; Table II).

ELISA. The serum levels of TNF-R1, Axl and TIMP-2 were further confirmed by ELISA. Results revealed that patients with preeclampsia showed significantly higher serum TNF-R1 levels $(288.06 \pm 78.30 \mathrm{pg} / \mathrm{ml})$ than women with gestational hypertension $(229.81 \pm 47.65, \mathrm{P}=0.005)$ and healthy pregnant controls $(247.48 \pm 59.00, \mathrm{P}=0.009)$ (Fig. 2A). Serum Axl levels were also markedly increased in preeclamptic patients $(2.28 \pm 0.25 \mathrm{ng} / \mathrm{ml})$ when compared to the gestational hypertensiven subjects $(2.05 \pm 0.21 \mathrm{ng} / \mathrm{ml})$ and healthy pregnant subjects $(2.11 \pm 0.28 \mathrm{ng} / \mathrm{ml}, \mathrm{P}=0.005)$ (Fig. 2B). Additionally, preeclamptic patients had higher TIMP-2 levels $(3.33 \pm 1.01 \mathrm{ng} / \mathrm{ml})$ as compared to gestational hypertension patients $(3.13 \pm 0.56 \mathrm{ng} / \mathrm{ml})$ and healthy pregnant women $(3.00 \pm 0.49 \mathrm{ng} / \mathrm{ml})$, but there was no significant differ- ence among the three study groups $(\mathrm{F}=1.285, \mathrm{P}=0.283>0.05)$ (Fig. 2C).

\section{Discussion}

Preeclampsia is a pregnancy-specific syndrome characterized by hypertension and proteinuria. It occurs in 3-5\% of pregnancies and leads to high maternal and fetal morbidity and mortality (1). In the past two decades, studies have revealed that preeclampsia is a multi-systemic syndrome with complex pathophysiological changes, such as endothelial dysfunction, inflammatory response, activation of the coagulation system and metabolic alteration (2). It is widely believed that the pathophysiological changes in preeclampsia may result from the abnormal expression of certain proteins (3). Thus, comparing the systemic immune balance by simultaneously measuring cytokines, chemokines and other inflammatory markers in the serum of preeclampsia women to that of women with normal pregnancy is of interest. 

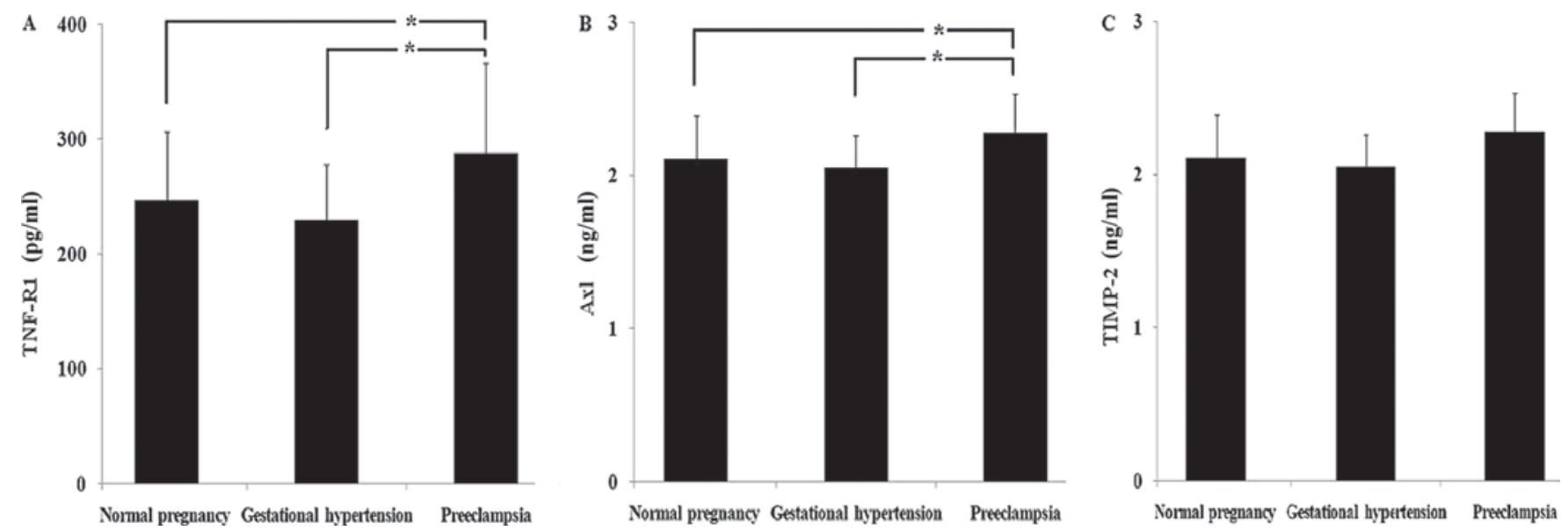

Figure 2. Serum protein levels of healthy pregnant control (hatched bar) and preeclamptic patients (dotted bar) was determined by ELISA. (A) sTNF-R1 levels were markedly increased in the preeclamptic patients when compared to the healthy pregnant controls. (B) Axl levels were dramatically increased in the preeclamptic patients. (C) TIMP-2 levels were increased in the preeclamptic patients when compared to the healthy pregnant controls, but there was no statistically significant difference between the two study groups. ${ }^{*} \mathrm{P}<0.05$.

Our findings showed significant elevation of serum Axl in preeclampsic women as compared to those with a normal pregnancy. To our knowledge, serum Axl has never been measured in patients with preeclampsia. Axl is a member of the Tyro3, Axl and Mertk (TAM) family of receptor tyrosine kinases (RTKs) and expressed in endothelial cells, vascular smooth muscle cells and fibroblasts in the vessel wall $(5,6)$. The TAM family of RTKs regulates an intriguing mix of processes, including cell proliferation/survival, cell adhesion and migration, clot stabilization and regulation of inflammatory cytokine release. The endogenous ligand for Axl is growth arrest specific protein 6 (Gas6). Axl and Gas6 are mainly expressed in endothelial cells, where they are of importance for endothelial activation (7). A study of Melaragno et al for the first time reported that Axl and Gas6 expression was regulated in response to vascular injury (6). Gas6 is also involved in the phagocytosis of apoptotic cells $(8,9)$, and increased circulating Gas6 may be a sign of up-regulation of Gas6 because of increased apoptosis. Axl has been shown to bind and inhibit Gas6 in a variety of experiments (10), and increased serum Axl is associated with the enhancement of Gas6-mediated signaling. Whether the increased internalization of Axl is attributed to the increased Gas6 expression remains to be elucidated.

Matrix metalloproteinases (MMPs) are a family of zinc and calcium-dependent endopeptidases involved in the remodeling and physiological homeostasis of the extracellular matrix (ECM) (11). MMP activity is predominantly modulated by their specific tissue inhibitors (TIMPs). The balance between MMPs and TIMPs is likely to play an important role in the remodeling of uterine arteries in pregnancy, and it may represent the means by which vasodilatation is maintained in later pregnancy (12). It has been confirmed that MMP-2 and TIMP-1 expression is significantly increased in preeclampsic patients $(13,14)$. Changes in circulating levels of MMP-9, TIMP-1 and TIMP-2 have also been noted in gestational hypertensive patients (15). Merchant and Davidge found a significantly enhanced release of MMP-2, TIMP-1 and TIMP-2 from the umbilical vein endothelial cells of preeclamptic women when compared to normotensive women (16). Higher amniotic fluid MMP-2 and TIMP-2 levels have been found in women who eventually develop preeclampsia (17). Increase in TIMP-2 has been noted during the physiologic placentation, further supporting the hypothesis that TIMP-2 plays a pivotal role in decidualization. Hurst and Palmay observed that TIMP-2 was strongly expressed in primary decidual tissues and modulated trophoblastic invasion (10), whereas Okamoto et al demonstrated that both the mRNA and protein expression of TIMP-2 was markedly decreased in hydatidiform mole and choriocarcinoma tissues, suggesting that the imbalance between MMP and TIMP may be involved in the pathogenesis of these diseases (18). In the present study, our findings confirmed the TIMP-2 was significantly increased in patients with preeclampsia, which is consistent with previous studies, suggesting that elevation of TIMP-2 may contribute to the inadequate trophoblast invasion and physiologic remodeling of spiral arteries that is central to the pathophysiology of preeclampsia.

A normal pregnancy is accompanied by an inflammatory response, which is exaggerated in the case of preeclampsia. Th1-type cytokines, such as tumor necrosis factor- $\alpha$ (TNF- $\alpha$ ), induce trophoblastic apoptosis and restrain differentiation and invasion of trophoblasts, thus resulting in the incomplete invasion of trophoblasts to spiral arteries and shallow implantation of placenta, which are integral pathologies of preeclampsia (19). TNF- $\alpha$ levels were found to be higher in preeclamptic women than in normotensive controls in several studies $(20,21)$. TNF- $\alpha$ functions by interacting with TNF receptors. Different TNF- $\alpha$ receptors have distinct biological effects: the 55-kDa TNF receptor (TNF-R1) induces apoptosis, and the $75-\mathrm{kDa}$ TNF receptor (TNF-R2) induces proliferation through activating the transcription factor- $\mathrm{\kappa B}$ (22). Shedding of these soluble receptors of TNF- $\alpha$ from the cell membranes plays a role in the regulation of biological effects of TNF- $\alpha$ by decreasing its availability as a ligand $(23,24)$. Moreover, plasma or serum concentrations of soluble TNF-Rs are considered as markers for excessive TNF biological activity, since these receptors have a longer half-life than their ligand.

Several studies have reported that the maternal serum levels of both TNF- $\alpha$ and TNF-R1 are significantly increased 
in preeclampsic patients when compared to normotensive controls $(25,26)$. While certain studies report increased TNF- $\alpha$ or TNF-R1 levels at as early as the first trimester in patients who subsequently develop preeclampsia, others reveal no significant difference between preeclampsic patients and controls $(27,28)$. Leal et al found that maternal serum TNF-R1 levels at 11-13 weeks gestational age was increased in pregnant subjects developing preeclampsia, but the TNF-R1 levels were not associated with the degree of impairment in placental perfusion or the severity of preeclampsia (29). Our findings were consistent with the above-mentioned studies and supported the hypothesis that intravascular inflammation is a mechanism of preeclampsia.

It is puzzling that we were unable to find any significant differences in the serum levels of other factors between preeclampsic women and healthy pregnant women, such as immunological markers during preeclampsia studied in previous studies (i.e., IL-1, IL-2, IL-4, IL-6, IL-8, IL-10, IFN- $\gamma$ and $\mathrm{TNF}-\alpha$ ). Further studies are required to confirm the role of these factors in the pathogenesis of preeclampsia.

In conclusion, our findings confirm that elevated TIMP-2 in preeclampsia may attribute to inadequate trophoblast invasion. The increase in serum TNF-R1, a pro-inflammatory cytokine, in preeclampsia women as compared to healthy pregnant women, supports the hypothesis that preeclampsia is associated with an increase in inflammatory responses. Notably, our results also revealed an increase in Axl, suggesting that Axl may serve as a new marker of endothelial activation in patients with preeclampsia. Taken together, our results indicate that preeclampsia is a systemic maternal disease. Although the etiology of preeclampsia is not completely clear, an important pathophysiologic feature of preeclampsia is systemic inflammation, which subsequently results in widespread endothelial dysfunction.

\section{Acknowledgements}

This study was supported by the Beijing Nova Star Program (2008B66), the Beijing Elitist Fund (20081D0301000086), the Beijing Obstetrics and Gynecology Hospital and the Doctoral Fund of the Ministry of Education of China (20070025003).

\section{References}

1. Roberts JM and Cooper DW: Pathogenesis and genetics of preeclampsia. Lancet 357: 53-56, 2001.

2. MacKay AP, Berg CJ and Atrash HK: Pregnancy-related mortality from preeclampsia and eclampsia. Obstet Gynecol 97: 533-538, 2001.

3. Wang A, Rana S and Karumanchi SA: Preeclampsia: the role of angiogenic factors in its pathogenesis. Physiology (Bethesda) 24 147-158, 2009

4. Conrad KP and Benyo DF: Placental cytokines and the pathogenesis of preeclampsia. Am J Reprod Immunol 37: 240-249, 1997

5. Lemke G and Rothlin CV: Immunobiology of the TAM receptors. Nat Rev Immunol 8: 327-336, 2008.

6. Melaragno MG, Wuthrich DA, Poppa V, et al: Increased expression of Axl tyrosine kinase after vascular injury and regulation by $\mathrm{G}$ protein-coupled receptor agonists in rats. Circ Res 83: 697-704, 1998.
7. Seitz HM, Camenisch TD, Lemke G, et al: Macrophages and dendritic cells use different Axl/Mertk/Tyro3 receptors in clearance of apoptotic cells. J Immunol 178: 5635-5642, 2007.

8. Hall MO, Obin MS, Heeb MJ, et al: Both protein S and Gas6 stimulate outer segment phagocytosis by cultured rat retinal pigment epithelial cells. Exp Eye Res 81: 581-591, 2005.

9. Sainaghi PP, Castello L, Bergamasco L, et al: Gas6 induces proliferation in prostate carcinoma cell lines expressing the Axl receptor. J Cell Physiol 204: 36-44, 2005.

10. Hurst PRand Palmay RD: Matrix metalloproteinases and their endogenous inhibitors during the implantation period in the rat uterus. Reprod Fertil Dev 11: 395-402, 1999.

11. Mott JD and Werb Z: Regulation of matrix biology by matrix metalloproteinases. Curr Opin Cell Biol 16: 558-564, 2004.

12. Chen L, Belton RJ and Nowak RA: Basigin-mediated gene expression changes in mouse uterine stromal cells during implantation. Endocrinology 150: 966-976, 2009.

13. Montagnana M, Lippi G, Albiero A, et al: Evaluation of metalloproteinases 2 and 9 and their inhibitors in physiologic and pre-eclamptic pregnancy. J Clin Lab Anal 23: 88-92, 2009.

14. Myers JE, Merchant SJ, Macleod M, et al: MMP-2 levels are elevated in the plasma of women who subsequently develop preeclampsia. Hypertens Pregnancy 24: 103-115, 2005.

15. Redman CW, Sacks GP and Sargent IL: Preeclampsia: an excessive maternal inflammatory response to pregnancy. Am J Obstet Gynecol 180: 499-506, 1999.

16. Merchant SJ and Davidge ST: The role of matrix metalloproteinases in vascular function: Implications for normal pregnancy and preeclampsia. BJOG 111: 931-939, 2004

17. Noel A, Maillard C, Rocks N, et al: Membrane associated proteases and their inhibitors in tumour angiogenesis. J Clin Pathol 57: 577-584, 2004.

18. Okamoto T, Niu R, Yamada S, et al: Reduced expression of tissue inhibitor of metalloproteinase (TIMP)-2 in gestational trophoblastic diseases. Mol Hum Reprod 8: 392-398, 2002.

19. Seki H, Matuoka K, Inooku H, et al: TNF- $\alpha$ from monocyte of patients with pre-eclampsia-induced apoptosis in human trophoblast cell line. J Obstet Gynaecol Res 33: 408-416, 2007.

20. Peraçoli JC, Rudge MV and Peraçoli MT: Tumor necrosis factoralpha in gestation and puerperium of women with gestational hypertension and pre-eclampsia. Am J Reprod Immunol 57: 177-185, 2007.

21. Sibai B, Romero R, Klebanoff MA, et al: Maternal plasma concentrations of the soluble tumor necrosis factor receptor 2 are increased prior to the diagnosis of preeclampsia. Am J Obstet Gynecol 200: 630-638, 2009.

22. Bazzoni $\mathrm{F}$ and Beutler $\mathrm{B}$ : The tumor necrosis factor ligand and receptor families. N Engl J Med 334: 1717-1725, 1996.

23. Van Zee KJ, Kohno T, Fischer E, et al: Tumor necrosis factor soluble-receptors circulate during experimental and clinical inflammation and can protect against excessive tumor necrosis factor alpha in vitro and in vivo. Proc Natl Acad Sci USA 89: 4845-4849, 1992.

24. Aderka D, Sorkine P, Abu-Abid S, et al: Shedding kinetics of soluble tumor necrosis factor (TNF) receptors after systemic TNF leaking during isolated limb perfusion. Relevance to the pathophysiology of septic shock. J Clin Invest 101: 650-659, 1998.

25. Serin IS, Ozcelik B, Basbug M, et al: Predictive value of tumor necrosis alpha (TNF-alpha) in preeclampsia. Eur J Obstet Gynecol Reprod Biol 100: 143-145, 2002.

26. Schipper EJI, Bolte AC, Schalkwijk CG, et al: TNF-receptor levels in preeclampsia result of a longitudinal study in high-risk women. J Matern Fetal Neonatal Med 18: 283-287, 2005.

27. Williams MA, Farrand A, Mittendorf R, et al: Maternal second trimester serum tumor necrosis factor-alpha soluble receptor p55 (sTNFp55) and subsequent risk of preeclampsia. Am J Epidemiol 149: 323-329, 1999.

28. Poon LC, Kametas NA, Valencia C, et al: Hypertensive disorders in pregnancy: screening by biophysical and biochemical markers at 11-13 weeks. Ultrasound Obstet Gynecol 35: 662-670, 2010.

29. Leal AM, Poon LC, Frisova V, et al: First-trimester maternal serum tumor necrosis factor receptor-1 and pre-eclampsia. Ultrasound Obstet Gynecol 33: 135-141, 2009. 